\title{
Cross-protection of cotton against Verticillium wilt by Verticillium nigrescens
}

\author{
Ioannis Vagelas*, Stefanos Leontopoulos \\ Department of Agronomy Technology, Laboratory of Plant Protection, Technological Educational Institute of Thessaly, 41110, Larissa, Greece
}

\section{A B S T R A C T}

\begin{abstract}
Two species of plant pathogenic fungi causing Verticillium wilt of cotton, Verticillium dalhiae Kleb. and V. nigrescens Pethybr., proved aggressive and weakly pathogen of cotton, respectively, and were used in this study. Cotton cultivars cvs 4 S and Stoneville 453 , susceptible to Verticillium wilt disease, were treated with both organisms in order to determine possible cross protection effects of $V$. nigrescens against $V$. dahliae. Results showed that the cotton plants which were inoculated on the same day as $V$. dahliae prior to inoculation by $V$. nigrescens were showing aggressive wilt symptoms of Verticillium wilt of cotton. However, the plants inoculated on the same day as $V$. nigrescens prior to inoculation by $V$. dahliae resulted low to mild wilt symptoms. Control of Verticillium wilt of cotton was obtained when $V$. nigrescens was inoculated four days prior to inoculation by $V$. dalhiae. Those promising results where further explained by data obtained from the transpiration rates of the mass flow of sap in cotton stems and demonstrated that conidia of $V$. nigrescens could protect the cotton plants from virulent conidia of $V$. dahliae.
\end{abstract}

Keywords: Biocontrol; Vascular diseases; Defense mechanisms induced by fungi

\section{INTRODUCTION}

Verticillium wilt caused by Verticillium dalhiae Kleb., is a well-known serious disease of many economical crops, especially of cotton where it can reduce cotton yield greatly under certain environmental conditions (Pegg, 1984; Bhat and Subbarao, 1999). The fungus is widespread in most cotton cultivated areas and is one of the greatest threats to cotton production worldwide (Erdogan and Benlioglum, 2010) as well as in cotton areas in Greece where this disease is one of the main constraints to cotton production especially in the region of Thessaly (Tjamos et al., 2000).

Most cotton plants are asymptomatic at initial infection (Shen, 1992; Xiao et al., 1998; Ma, 2007), thus, cotton yield losses can be reduced effectively when cotton Verticillium infection is predicted early and accurately, and prophylactic measures are properly taken (Jing and Huang, 2010).

However, according to Paplomatas et al., (1992) when infection occurs at later stages infected plants usually exhibit symptoms of marginal necrosis in leaves, discoloration of the stem vascular bundles, decrease in photosynthesis and increase in respiration, resulting in a significant reduction of the plant biomass and significant loss in yield.

The study of the symptoms on the infected plants depends mainly on the manual investigation and sampling in fields which is time and effort consuming and difficult to practice for large areas. Thus, correlation analysis of leaf spectral reflectance and disease severity of cotton Verticillium has shown that there are a number of sensitive bands that spread in several spectrums (Ning et al., 2013).

In general, different methods of controlling Verticillium wilt of cotton plant like heat treatment, fumigation with broadspectrum biocides and eco-friendly friendly alternative methods like rhizobacteria (Weller, 1998; Fravel and Larkin, 2000; Landa et al., 2004) mycoparasites (Grunden et al., 2001; Rekanovic et al., 2007; Zheng et al., 2011) and endophytes (Yang et al., 2013) have been well-reported.

Furthermore, according to Xue et al., (2013) shown that the application of powdered biocontrol agent containing living actinomycetes could be useful for biocontrol of the plant pathogen in agricultural production. The isolates

\footnotetext{
*Corresponding author:

Ioannis Vagelas, Department of Agronomy Technology, Laboratory of Plant Protection, Technological Educational Institute of Thessaly,

41110, Larissa, Greece. E-mail: s_leontopoulos@yahoo.com
}

Received: 11 April 2015;

Revised: 22 June 2015;

Accepted: 26 June 2015;

Published Online: 26 June 2015 
successfully colonized the cotton rhizosphere in a wilt-sick field study when the powdered biocontrol agent was applied either as a seed coating or as a soil inoculation.

Moreover, planting resistant varieties is a possible strategy for protection of cotton from $V$. dabliae, but few upland cotton cultivars showed resistance towards Verticillium wilt (Bolek et al., 2005; Gore et al., 2009; Gao et al., 2011).

Furthermore, organic amendments in applied soil also reduced disease severity in both inoculated pots and naturally infested cotton field plots. According to Huang et al., (2006) the most effective control was achieved with crab shell (chitin), soybean stalk and alfalfa.

The aim of this study was to to determine possible cross protection effects of $V$. nigrescens against $V$. dabliae in susceptible cotton cultivars in the region of Thessaly, Greece.

\section{MATERIALS AND METHODS}

In the present study the severe pathogen ( $V$. dalbiae) was isolated, in the laboratory of plant protection of Technological Educational Institute of Thessaly (T.E.I.), several times from cotton plants showing symptoms of Verticillium wilt at several locations in central Greece. In order to determine protection against a virulence isolate of $V$. dalbiae, an isolate of $V$. nigrescens, a comparatively weaker vascular pathogen, recovered from cotton plants showing weak wilt symptoms, was tested. Following that we tested cross protection effects in cotton against disease induced by a virulent isolate of $V$. dalbiae with the weaker vascular pathogen $V$. nigrescens four days prior to inoculation with a challenger strain based on the idea presented (Melouk and Horner, 1975). Moreover, that cross protection effects were tested in process biochemical mechanisms, antifungal mechanisms, such as phytoalexins of cotton plants in response to inoculums of the aggressive pathogen ( $V$. dalhiae) as represented in previous research work (Zaki et al., 1972).

Both pathogens were isolated from cotton vascular tissues and grown on PDA plates which were incubated in darkness at $22^{\circ} \mathrm{C}$ for 20 days. Pathogenicity tests were determined by immersing cotton plant roots (shoot tip cutting) for $45 \mathrm{~min}$ in a Verticilliums solution, which contained $5 \times 10^{5}$ conidia/ $\mathrm{ml}$. This high spore suspension can affect plant tissues and cause Verticillium disease symptoms (Pegg and Brady, 2002). Treated plants were transplanted in pots and kept in a glasshouse with $28-30^{\circ} \mathrm{C}$ for 45 days. Two cotton (Gossypium birsutum L.) cultivars, " $4 \mathrm{~S}$ " and "Stoneville 453", susceptible to Verticillium wilt were used. The experiment was designed with seven treatments and 21 replications, as follows:

a) Immersing the root cut ends into $V$. dabliae $(V d)$, in conidia suspension $\left(5 \times 10^{5}\right.$ conidia $\left./ \mathrm{ml}\right)$, for $45 \mathrm{~min}$ (Melouk and Horner, 1975).

b) Immersing the root cut ends into $V$. nigrescsens $(V n)$, in conidia suspension $\left(5 \times 10^{5}\right.$ conidia $\left./ \mathrm{ml}\right)$, for $45 \mathrm{~min}$.

c) Immersing the root cut ends into $V$. nigrescens, in conidia suspension $\left(5 \times 10^{5}\right.$ conidia $\left./ \mathrm{ml}\right)$, for $45 \mathrm{~min}$ and subsequently, on the same day, inoculation with $V$. dabliae $(V n+V d)$, by adding spore suspension $\left(5 \times 10^{5}\right.$ spores $\left./ \mathrm{ml}\right)$ in the pot $(10 \mathrm{ml} /$ pot $)$.

d) Immersing the root cut ends into $V$. nigrescens, in conidia suspension $\left(5 \times 10^{5}\right.$ conidia $\left./ \mathrm{ml}\right)$, for $45 \mathrm{~min}$ and after 4 days inoculation with $V$. dabliae $(V n+4 V d)$, by adding spore suspension $\left(5 \times 10^{5}\right.$ conidia $\left./ \mathrm{ml}\right)$ in the pot $(10 \mathrm{ml} /$ pot $)$.

e) Immersing the root cut ends into $V$. dabliae, in conidia suspension $\left(5 \times 10^{5}\right.$ conidia/ml), for $45 \mathrm{~min}$ and subsequently, on the same day, inoculation with $V$. nigrescens $(V d+V n)$, by adding spore suspension $\left(5 \times 10^{5}\right.$ conidia $\left./ \mathrm{ml}\right)$ in the pot $(10 \mathrm{ml} /$ pot $)$.

f) Immersing the root cut ends into $V$. dabliae, in conidia suspension $\left(5 \times 10^{5}\right.$ conidia/ml), for $45 \mathrm{~min}$ and after 4 days inoculation with $V$. nigrescens $(V n \rightarrow 4 V d)$, by adding spore suspension $\left(5 \times 10^{5}\right.$ conidia $\left./ \mathrm{ml}\right)$ in the pot $(10 \mathrm{ml} / \mathrm{pot})$.

g) Immersing the root cut ends into sterile water (Control plants).

Number of leaf discoloration (foliar damage by 0-5 rating scale where 0 : no foliar symptoms; 3 : $25 \%$ of plants showing evidence of leaf yellow; 5: severe foliar damage), stem vascular staining (darker in color by $1-4$ rating scale where 1: light vascular staining to 4 : vascular staining darker in color), stem height, diameter, fresh weight and dry weight of inoculated plants were assessed at the end of the experiment, after 45 days of incubation. All data were analysed by analysis of variance (ANOVA) and presented with graphs using Microsoft Excel.

Xylem sap flow investigation in cotton plants infected with or without Verticillium species was determined as follows. The study was carried out after 40 days of inoculation in eight periods (30 to 240 min, Fig. 4), using two random plants for each period. The probes of phytometric system LPS-03 Phytomonitor (PhyTech Ltd) was established into the stem up to a height of $20 \mathrm{~cm}$ from soil surface to measure sap flow density.

\section{RESULTS AND DISCUSSION}

The results showed that cotton plants inoculated with only $V$. nigrescens were symptomless, obtained significant high 
values for stem height, diameter, fresh and dry weight and significant less values for number of leaf discoloration and stem vascular staining compared to those cotton plants inoculated with only $V$. dalbiae (Figs. 1-3). When inoculation with $V$. nigrescens precedent $V$. dalbiae, mild wilt symptoms occurred in all cotton tested plants, agreeing with Korolev and Katan, (1999). Plants which were inoculated on the same day as $V$. nigrescens before the inoculation with $V$. dabliae were statistically different from those inoculated on the same day as $V$. dabliae before the inoculation with $V$. nigrescens, in number of leaf discoloration, stem vascular staining, diameter, fresh and dry weight (Figs. 1-3).

When $V$. nigrescens was inoculated four days after $V$. dalhiae, significant wilt symptoms were observed as measurements such as stem diameter, stem height, foliar damage, stem discolouration, stem dry weight and stem fresh weight were done (Figs. 1-3).

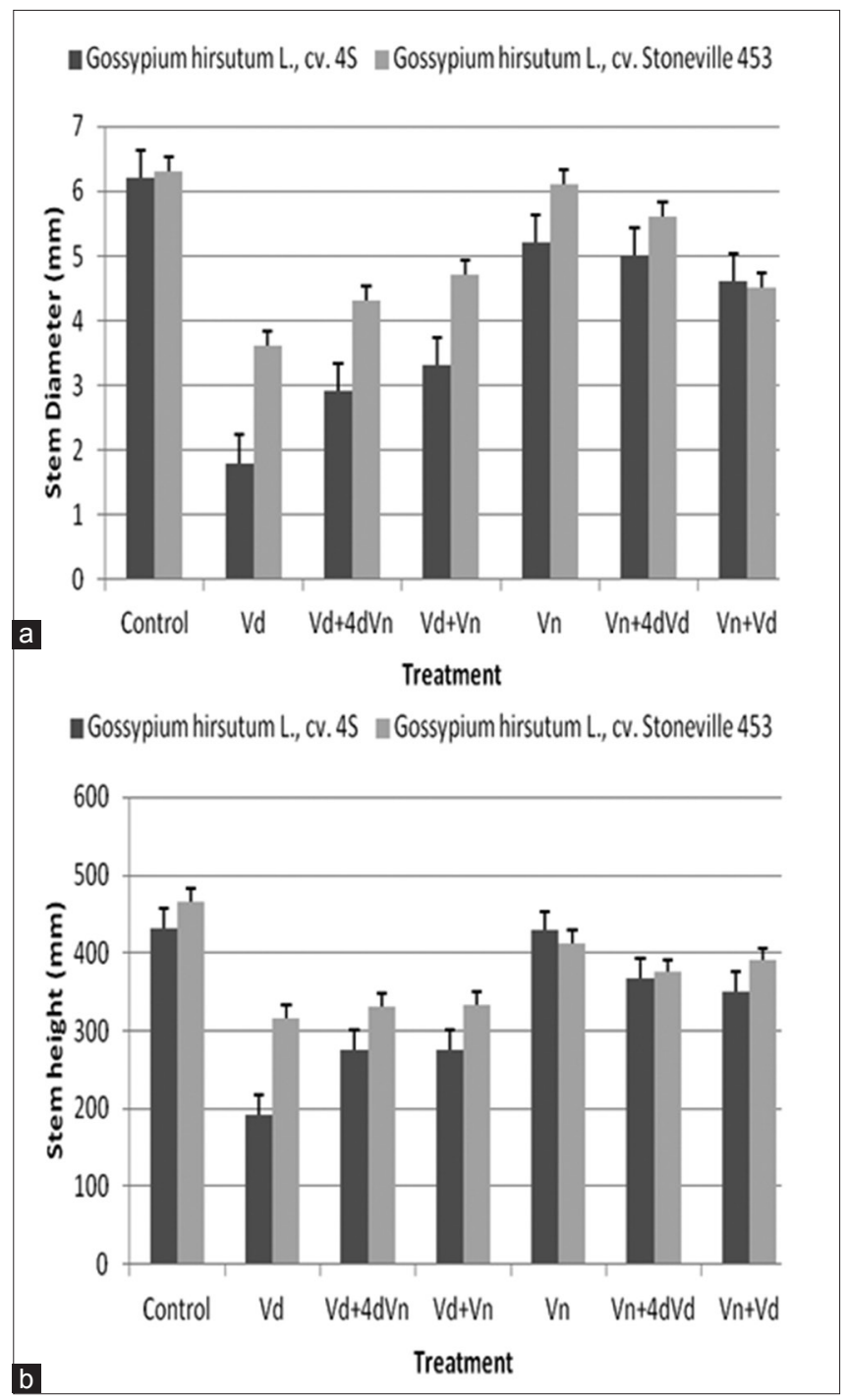

Fig 1. Cotton stems diameter (a) and height (b), in inoculated plants with $V$. nigrescens and V.dahliae.

Emir. J. Food Agric • Vol $27 \bullet$ Issue $9 \bullet 2015$
Moreover, the results of Figs. 1-3 also showed that when $V$. dalhiae was inoculated four days after $V$. nigrescens, a significant less wilt symptoms was observed, and we can say that $V$. nigrescens induced a crop protection effect against $V$. dalbiae when introduced first in cotton plant rhizosphere. As determined by measurement the transpiration rates of mass flow of sap in the cotton stem (Figs. 4), the rate of mass flow of sap increased significantly in plants inoculated with only $V$. nigrescens and in plant when $V$. dalbiae was inoculated four days after $V$. nigrescens. This is in agreement with previous research work, where cross protection effects were observed in peppermint when inoculation with $V$. nigrescens preceded inoculation with $V$. dabliae by two days (Melouk and Horner, 1975).

\section{CONCLUSION}

In the present investigation results show that it is possible to reduce disease induced by a virulent isolate of $V$. dalbiae, when inoculated first with a weak pathogen, $V$. nigrescens. It is believed that cross-protection of cotton to a severe isolate of $V$. dalbiae was possible due to accumulation into xylem of antifungal secondary metabolites in response to

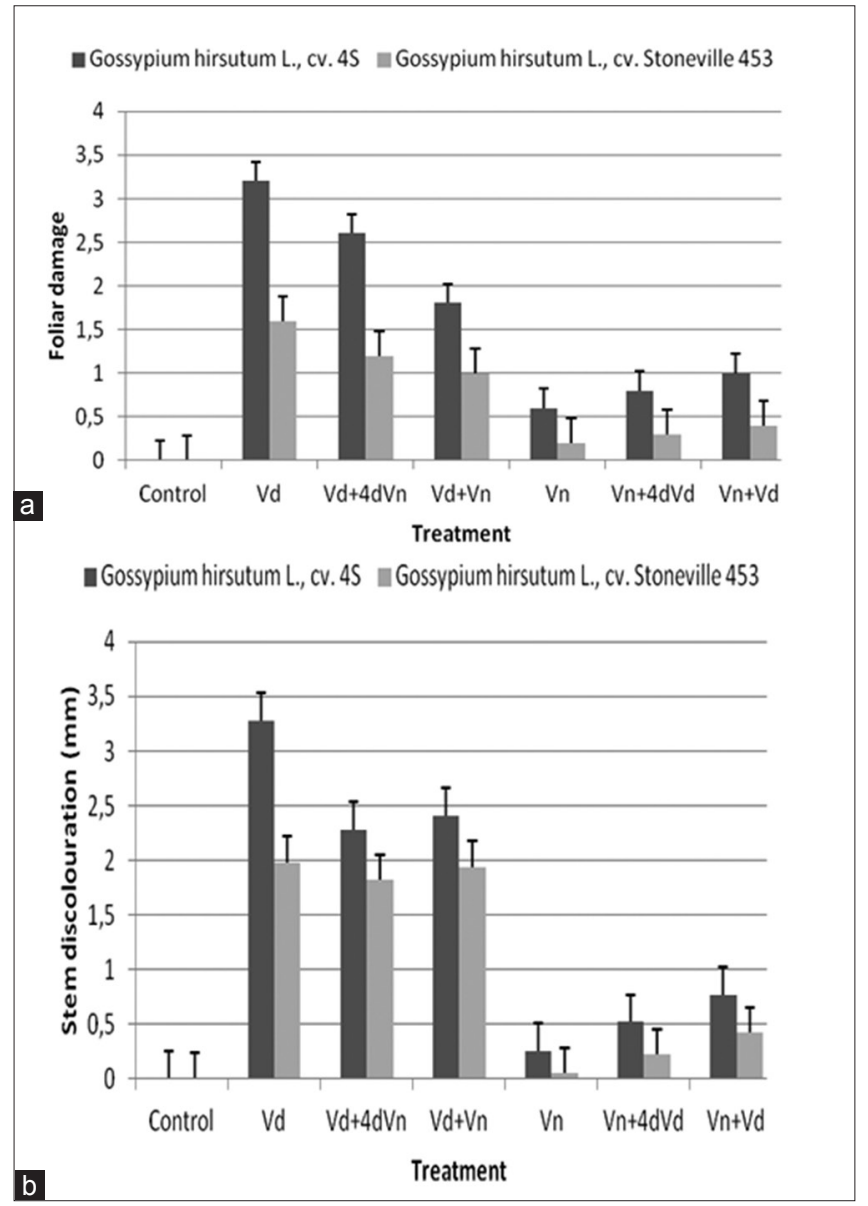

Fig 2. Cotton foliar damage (a) and stem discolorations (b), in inoculated plants with $V$. nigrescens and $V$.dahliae. 


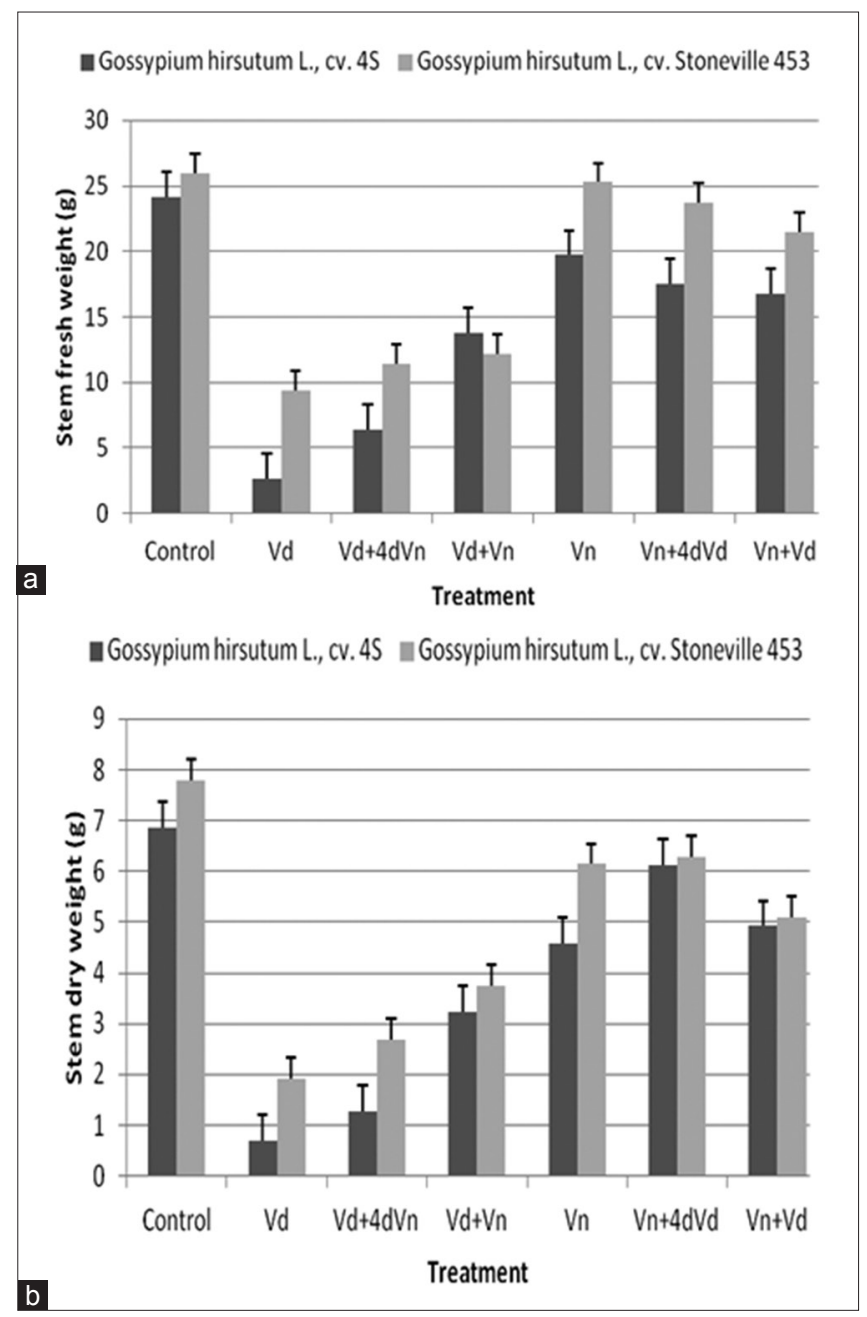

Fig 3. Cotton stems fresh weight (a) and dry weight (b), in inoculated plants with $V$. nigrescens and V.dahliae.

inoculation with $V$. nigrescens, (Zaki et al., 1972; Schnathorst and Mathre, 1996). Finally, we can concluded that the crossprotection phenomenon reported in the present study is a form of a biological control occurred in nature and may have application in control of wilt diseases in plant (Price and Sackston, 1989; Huertas-Gonzalez et al., 1999; Erdogan et al., 2013).

\section{Author contributions}

The work is a product of the intellectual environment of both authors which have contributed in various degrees to the analytical methods used, to the research concept, and to the experiment design. Dr. I. Vagelas designed the study, developed the methodology, performed the analysis while Dr. S. Leontopoulos collected the data, and made the isolations. Both authors contributed in writing the manuscript.

\section{REFERENCES}

Bhat, R. G. and K.V. Subbarao. 1999. Host range specificity in Verticillium dahliae. Phytopathology. 89: 1218-1225.

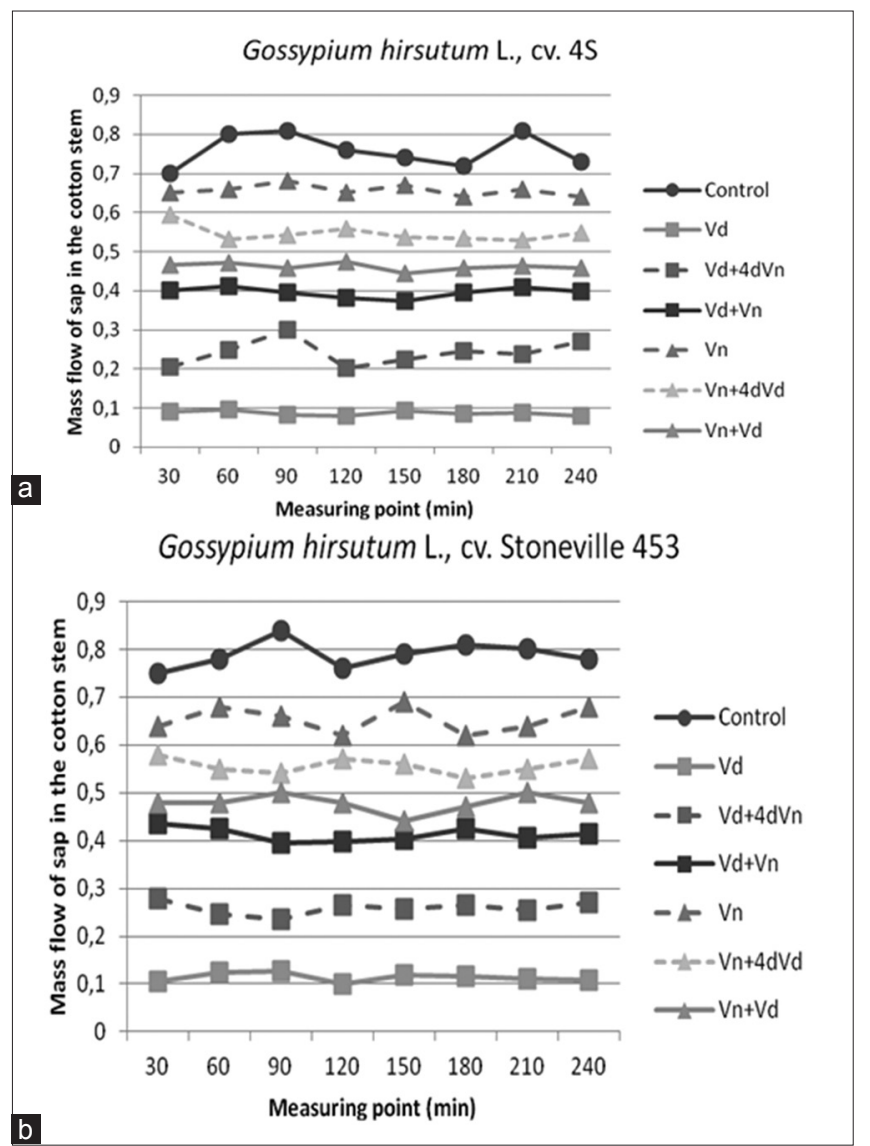

Fig 4. Mass flow of sap in the cotton Stems inoculated with $V$. nigrescens and V.dahliae.

Bolek, Y., K. M. El-Zik and A. E. Pepper. 2005. Mapping of Verticillium wilt resistance genes in cotton. Plant Sci. 168: 1581-1590.

Erdogan, O. and K. Benlioglu. 2010. Biological control of Verticillium wilt on cotton by the use of fluorescent Pseudomonas spp. under field conditions. Biol. Cont. 53: 39-45.

Erdogan, O., S. Nemli, T. Oncu and B. Tanyolac. 2013. Genetic variation among pathotypes of Verticillium dahliae Kleb. from cotton in western Turkey revealed by AFLP. Can. J. Plant Path. 35: 354-362.

Fravel, D. R. and R. P. Larkin. 2000. Effect of sublethal stresses on microsclerotia of Verticillium dahliae. In: Tjamos, E. C., R. C. Rowe., J. B. Heale and D. R. Fravel., (Eds.). Advances in Verticillium Research and Disease Management. American Phytopathological Society (APS) Press, St. Paul, Minessota., Pp. 301-306.

Gao, X., T. Wheeler., Z. Li., C.M. Kenerley., P. He. and L. Shan. 2011. Silencing GhNDR1 and GhMKK2 compromised cotton resistance to Verticillium wilt. Plant J. 66: 293-305.

Gore, E. M., O. K. Caner., N. Altın., M. H. Aydın., O. Erdogan., F. Filizer and A. Buyukdogerlioglu. 2009. Evaluation of cotton cultivars for resistance to pathotypes of Verticillium dahliae. Crop Prot. 28: 215-219.

Grunden, E., W. Chen and J. L. Crane. 2001. Fungi colonizing microsclerotia of Verticillium dahliae in urban environments. Fungal Divers. 8: 129-141.

Huanga, J., H. Lib and H. Yuan. 2006. Effect of organic amendments on Verticillium wilt of cotton. Crop Prot. 25: 1167-1173.

Huertas-Gonzalez, M. D., M. C. Ruiz-Roldan., A. Di Pietro and Emir. J. Food Agric • Vol $27 \bullet$ Issue 9 • 2015 
M. I. G. Roncero. 1999. Cross protection provides evidence for race-specific avirulence factors in Fusarium oxysporum. Phys. Mol. Plant Path. 54: 63-72.

Jing, X., W. J. Huang and Y. Ju. 2010. Remote sensing monitoring severity level of cotton Verticillium wilt based on partial least squares regressive analysis. Trans. CSAE. 26: 229-235.

Jin, N., W. Huang., Y. Ren., J. Luo., Y. Wu., Y. Jing and D. Wang. 2013. Hyperspectral identification of cotton Verticillium disease severity. Optik. 124: 2569-2573.

Landa, B. B., J. A. Navas-Cortés and R. M. Jiménez-Díaz. 2004. Influence of temperature on plant: Rhizobacteria interactions related to biocontrol potential for suppression of Fusarium wilt of chickpea. Plant Pathol. 53: 341-352.

Ma, C. 2007. Studying on Verticillium wilt and Fusarium wilt of cotton. In: Jian, G. L., J. R. Yang., J. Feng and J. X. He. (Eds.). Breeding of Cotton Resistant Varieties. Vol. 1. Chinese Agricultural Press, Beijing, Pp. 185-246.

Melouk, H. A. and C. A. Horner. 1975. Cross protection in mints by Verticillium nigrescens against $V$. dahliae. Phytopathology. 65: 767-769.

Paplomatas, E. J., D. M. Bassett., J. C. Broome and J. E. Devay. 1992. Incidence of Verticillium wilt and yield losses of cotton cultivars (Gossypium hirsutum) based on soil inoculum density of Verticillium dahliae. Phytopathology. 82: 1417-1420.

Pegg, G. F. 1984. The impact of Verticillium diseases in agriculture. Phytopathol. Mediterr. 23: 176-192.

Pegg, G. F. and B. L. Brady. 2002. Verticillium Wilts. CABI Publishing, Oxon, UK.

Price, D. and W. E. Sackston. 1989. Cross protection among strains of Verticillium dahliae on sunflower. Vascular wilt diseases of plants. NATO ASI Series. 28: 229-235.

Rekanovic, E., S. Milijasevic., B. Todorovic and I. Potocnik. 2007.
Possibilities of biocontrol and chemical control of Verticillium wilt in pepper. Phytoparasitica. 35: 436-441.

Shen, Q. Y. 1992. Cotton disease-basic research and protection. In: Deng, Y. S., Q. J. Li and Q. Y and Chen, Q. Y. (Eds.). Identification of the Resistance of Cotton Varieties. Vol. 1. Science Press, Beijing, Pp. 268-269.

Schnathorst, W. C. and D. E. Mathre. 1996. Cross protection in cotton with strains of Verticillium albo-atrum. Phytopathology. 56: 1204-1209.

Tjamos, E. C., R.C. Rowe., J. B. Heale and D. R. Fravel. 2000. Advances in Verticillium Research and Disease Management. APS Press. The American Phytopathological Society, St. Paul, MN, p. 378.

Weller, D. M. 1998. Biological control of soilborne plant pathogens in the rhizosphere with bacteria. Ann. Rev. Phytopathol. 26: 379-407.

Xiao, C. L., K. V. Subbarao., K. F. Schulbach and S. T. Koike. 1998 Effects of crop rotation and irrigation on Verticillium dahliae microsclerotia in soil and wilt in cauliflower. Phytopathology. 88: 1046-1055.

Xue, L., Q. Xue, Q. Chen, C. Lin, G. Shen and J. Zhao. 2013. Isolation and evaluation of rhizosphere actinomycetes with potential application for biocontrol of Verticillium wilt of cotton. Crop Prot. 43: 231-240.

Yang, P., Z. Sun., S. Liu., H. Lu., Y. Zhou and M. Sun. 2013. Combining antagonistic endophytic bacteria in different growth stages of cotton for control of Verticillium wilt. Crop Prot. 47: 17-23.

Zaki, A. I., N. T. Keen and D. C. Erwin. 1972. Implication of vergosin and hemigossypol in the resistance of cotton to Verticillium alboatrum. Phytopathology. 62: 1402-1406.

Zheng, Y., Q. Y. Xue., L. L. Xu., Q. Xu., S. Lu., C. Gu and J. H. Guo. 2011. A screening strategy of fungal biocontrol agents towards Verticillium wilt of cotton. Biol. Cont. 56: 209-216. 